\title{
Ferritin Level in Pre and Postmenopausal Women Attending Usmanu Danfodiyo University Teaching Hospital Sokoto
}

\author{
Erhabor $\mathbf{0}^{1 *}$, Ibrahim $\mathbf{K}^{1}$, Isah $\mathbf{N}^{1}$, Abdulrahaman $\mathbf{Y}^{1}$, Zama $\mathbf{I}^{1}$, \\ Buhari $\mathbf{H}^{1}$, Onuigwe UF${ }^{1}$, Ibrahim BA ${ }^{1}$, Ahmed M $^{1}$, Okwesili A ${ }^{1}$, \\ Imoru $\mathbf{M}^{1}$, Udomah FA ${ }^{1}$, Hassan $\mathbf{M}^{2}$, Ian-Gobo $\mathbf{M}^{3}$, Echonwere $\mathrm{B}^{3}$, \\ Egenti $\mathrm{BN}^{4}$ and Fredrick $\mathrm{C}^{4}$
}

Research Article

Volume 1 Issue 2

Received Date: July 15, 2017

Published Date: November 22, 2017

DOI: $10.23880 /$ hij-16000110

${ }^{1}$ Department of Haematology, Usmanu Danfodiyo University, Nigeria

2Department of Obstetrics and Gynaecology, Usmanu Danfodiyo University Teaching Hospital, Nigeria ${ }^{3}$ Department of Medical Laboratory Science, Rivers State University of Science and Technology, Nigeria ${ }^{4}$ College of Health Sciences, University of Abuja, Nigeria

*Corresponding author: Osaro Erhabor, Department of Haematology and Blood Transfusion Science, Faculty of Medical Laboratory Science, Usmanu Danfodiyo University, Sokoto, Nigeria, E-mail: n_osaro@yahoo.com

\section{Abstract}

Healthy individuals possess 3-4g of iron in his/her iron store, mostly in haemoglobin (oxygen-carrying pigment of blood) which is the most essential requirement of blood. Ferritin is a ubiquitous intracellular protein that stores iron and releases it in a controlled fashion. Serum ferritin is an indirect marker of the total amount of iron stored in the body and hence is used as a diagnostic marker for iron deficiency anaemia. This study was carried out to determine the level of serum ferritin in pre-and postmenopausal women attending Usmanu Danfodiyo University Teaching Hospital Sokoto. The study was conducted among one hundred and fifty women (75 premenopausal and 75 postmenopausal) with mean age $43.99 \pm 19.22$. The age range for premenopausal and postmenopausal women was 18-49 and 50-87 years respectively. The serum ferritin levels were compared among the premenopausal and postmenopausal subjects. The serum ferritin was significantly higher among postmenopausal women $47.38 \pm 43.00$ compared to premenopausal women $21.96 \pm 20.15(\mathrm{p}=0.01)$. The prevalence of anaemia based on serum ferritin level was higher among premenopausal women (8.7\%) compared to postmenopausal women (2.7\%). Low ferritin level $<3.5 \mathrm{ng} / \mathrm{ml}$ was higher among Hausa /Fulani (6.02\%) compared to other ethnic groups. The difference however was not statistically significant ( $\mathrm{p}=0.91$ ). Low ferritin level was higher among premenopausal women in the 25-34 years age group compared to other age groups. This study has shown that anaemia based on serum ferritin level of $<3.5 \mathrm{ng} / \mathrm{ml}$ was significantly higher among premenopausal compared to postmenopausal women. Ferritin level $<3.5 \mathrm{ng} / \mathrm{ml}$ was higher among Hausa /Fulani (6.02\%) and among premenopausal women in the 25-34 years age group. Serum ferritin should be used for the diagnosis and monitoring of iron deficiency anaemia in pre-and postmenopausal women. Ferritin level of $<3.5 \mathrm{ng} / \mathrm{ml}$ should be used as cutoff for the diagnosis of depleted iron store.

Keywords: Ferritin; Pre-and postmenopausal women; Usmanu Danfodiyo University Teaching Hospital; Sokoto 
Abbreviations: NIH: National Institutes of Health; HRT: Hormone-Replacement Therapy; DMT1: Divalent Metal Transporter1; HCP1: Haem Carrier Protein 1; IREG1: Iron Regulated Transporter 1; TIBC: Total Iron Binding Capacity; HCI: Hydrochloric Acid; HB: Haemoglobin

\section{Introduction}

Healthy individuals possess $3-4 \mathrm{~g}$ of iron in his/her iron store, mostly in haemoglobin (oxygen-carrying pigment of blood) which is the most essential requirement of blood. Ferritin is a ubiquitous intracellular protein that stores iron and releases it in a controlled fashion. The protein is produced by almost all living organisms, including algae, bacteria, higher plants, and animals. In humans, it acts as a buffer against iron deficiency and iron over load [1]. Ferritin is found in most tissues as a cytosolic protein, but small amounts are secreted into the serum where it functions as an iron carrier. Plasma ferritin is also an indirect marker of the total amount of iron stored in the body. Hence serum ferritin is used as a diagnostic test for iron deficiency anemia [2].

Iron deficiency is one of the most prevalent nutrient disorders. It affects approximately two billion people worldwide and is the most common cause of anemia (WHO) [3]. Although the prevalence of iron deficiency is greater in developing nations, it remains a health issue in industrialized countries as well. Because iron plays a key role in maternal and foetal health, understanding the factors that contribute to iron deficiency is particularly important in women of reproductive age. According to NHANES 1999-2000 data, the prevalence of iron deficiency in the United States was $16 \%$ and $12 \%$, respectively, in non-pregnant females aged 16-19 and 20-49 years (CDC, 2002). Women of child-bearing age are susceptible to iron deficiency due to periodic menstrual blood loss, and, in pregnant women, the increased iron requirements of the foetus.

In recent years, interest in the improvement of women's health has received great worldwide attention [4]. The commitment of the National Institutes of Health (NIH) and its Office of Research on Women's Health exemplifies the effort taken by the U.S. government and highlights the need for surveillance and screening programs that carefully monitor adverse effects in women. The health of girls and women is affected by developmental, physiological, and psychological age. Women's lives are marked by a continuum from intrauterine life to the elderly years: infancy, childhood and adolescence, menarche, reproductive life, the menopausal transition, postmenopausal years, the elderly and frail elderly. Across the life span of a woman, menopause probably has the greatest impact on health [5]. Menopause is a natural aging process during which a woman passes from the reproductive to the non-reproductive years. Despite this natural process, many women still experience menopausal symptoms such as vasomotor episodes or "hot flashes," as well as pathophysiologic conditions such as loss of bone mineral density and thinning and drying of skin [6].

One of the first observable physiological changes for menopause is the cessation of menstrual periods. Because of the reduction in ovarian functions, estrogen deficiency has been the main focus of menopausal research, interventions, and treatments. Yet, results of a meta-analysis of high-quality randomized controlled trials showed that estrogen-only or a combination with progestin hormone-replacement therapy (HRT) reduced hot flashes in $90 \%$ of pre-menopausal women, but in just $65 \%$ of postmenopausal women [5]. Moreover, overall bone turnover is significantly increased in pre-and postmenopausal women but in an imbalanced fashion. Bone reabsorption increases, at $90 \%$, and bone formation increases at only $45 \%$, resulting in a net loss of bone mineral density [7]. The exact mechanism through which bone formation after menopause cannot keep up with bone reabsorption remains unknown. Hormone Replacement Therapy (HRT) is partially effective in slowing bone loss in postmenopausal women [8]. The benefits and drawbacks of HRT remain controversial, and a substantial number of women have discontinued its use because of concerns about side effects [5]. Taking into consideration the partial alleviation and potential risk of HRT, we searched risk factors other than estrogen deficiency in menopausal symptoms and diseases.

Menstruation is a unique physiological phenomenon in young women, characterized by the periodic high levels of estrogen and the shedding of the endometrium. Because of this monthly blood loss, iron deficiency is prevalent in premenopausal women [9]. During premenopause, fewer eggs exist for the ovaries to stimulate, and menstrual periods become irregular. This period of fluctuation can last up to 10 years. Cessation of menstruation marks the later stage of premenopause. Because iron is no longer lost through menstruation, it accumulates in the body.

Ferritin, a marker of total body iron stores, is known to be associated with the risk of having metabolic syndrome and has been demonstrated to increase after the onset of menopause. Iron deficiency is the most common nutrient disorder, affecting nearly two billion people worldwide and is the most common cause of anaemia among women of child bearing age and preschool children (WHO) [3]. Premenopausal women are among those at greatest risk for iron deficiency anaemia 
due to low ferritin [10]. Plasma ferritin is also an indirect marker of the total amount of iron stored in the body. Hence serum ferritin is used as a diagnostic test for iron deficiency anemia [2]. Healthy individuals possess $3-4 \mathrm{~g}$ of iron in his/her iron store, mostly in haemoglobin (oxygen-carrying pigment of blood) which is the most essential requirement of blood. On the other hand, low or high level of iron-store (ferritin) found among the pre-and post-menopausal women are associated with iron deficiency and metabolic syndrome in pre-and post-menopausal women. However, in Sokoto State, there is paucity of data on iron stores of pre-and post-menopausal women. This study is therefore designed to assess serum ferritin level in preand post-menopausal women attending Usmanu Danfodiyo University Teaching Hospital Sokoto. The aim of this study is to determine the differences in ferritin level between pre-and postmenopausal women attending Usmanu Danfodiyo University Teaching Hospital Sokoto.

Iron is an essential trace metal in the human diet due to its obligate role in a number of metabolic processes. In the diet, iron is present in a number of different forms, generally described as haem (from haemoglobin and myoglobin in animal tissue) and non-haem iron (including ferric oxides and salts, ferritin and lactoferrin). Iron is an essential element involved in a broad range of biologically important reactions critical for cellular function and also plays fundamental role in oxygen transport. Disorders of iron homeostasis are among the most common human disorders [11]. Iron can be obtained from lean red meat, fish, poultry and iron-fortified grains such as cereals. Legumes and dark green vegetables, such as kale, collard greens and spinach, are part of a healthy diet. They also have high iron content. It is easier for the body to use the iron in meat than the iron in plant foods. To help the body use iron from plant foods, vitamin-C-rich foods, such as citrus fruits/juices, or a small amount of meat should be eaten at the same meal. Using cast-iron skillets for cooking can add iron to the food cooked. Coffee, tea, soda and excessive milk intake can reduce iron absorption and should be avoided, at meal times.

Most of the iron in the body is hoarded and recycled by the reticuloendothelial system, which breakdown aged red blood cells. However, this steady loss means that people must continue to absorb iron. They do so via a tightly regulated process that under normal circumstances protects against iron overload [12]. Dietary non-haem iron (mostly ferric) is reduced by the actions of the ferric reductaseduodenal cytochrome $b$ (Dcytb) and reducing agents in the diet to yield Fe2+, which subsequently enters the enterocytes via divalent metal transporter1(DMT1). Haem is absorbed via haem carrier protein 1(HCP1) and broken down by haemoxygenase 1 to liberate $\mathrm{Fe} 2+$ (this joins a common pool with iron from the non-haem pathway) and bilirubin. If body iron stores are high, iron may be diverted into ferritin and lost when the cell is shed at the villus tip. Alternatively, iron passes into the labile iron pool and is subsequently processed for efflux via iron regulated transporter 1(IREG1) as (Fe2+). The exiting iron is re-oxidised to $\mathrm{Fe} 3+$ to enable loading onto transferrin. The absorption of dietary iron is a variable and dynamic process. The amount of iron absorbed compared to the amount ingested is typically low, but may range from $5 \%$ to $35 \%$ depending on circumstances and type of iron. The efficiency with which iron is absorbed varies depending on the source. Generally, the best absorbed forms of iron come from animal products. Absorption of dietary iron in iron salt form (as in most supplements) varies somewhat according to the body's need for iron, and is usually between $10 \%$ and $20 \%$ of iron intake. Absorption of iron from animal products, and some plant products, is in the form of haeme iron, and is more efficient, allowing absorption of $15 \%$ to $35 \%$ of intake. Haeme iron in animals is from blood and haeme containing proteins in meat and mitochondria, whereas in plants, haeme iron is present in mitochondria in all cells that use oxygen for respiration [13].

The human body's rate of iron absorption appears to respond to a variety of interdependent factors, including total iron stores, the extent to which the bone marrow is producing new red blood cells, the concentration of haemoglobin in the blood, and the oxygen content of the blood. The body also absorbs less iron during times of inflammation. Recent discoveries demonstrate that hepcidin of ferroportin is responsible for the syndrome of anaemia of chronic diseases.

The vast majority of body iron is distributed in the haemoglobin of red blood cells and developing erythroid cells serve in oxygen transport [14].

\section{Laboratory Diagnosis of Iron Ferritin}

Ferritin is a ubiquitous intracellular protein that stores iron and releases it in a controlled fashion. The amount of ferritin stored reflects the amount of iron stored. The protein is produced by almost all organisms, including algae, bacteria, higher plants and animals. In humans, it acts as buffer against iron deficiency and iron overload. It has 24 subunits that are present in every cell type [15]. The function and structure of the expressed ferritin protein varies in different cell types. This is controlled primarily by how much mRNA is translated, and how stable the mRNA. mRNA concentration is further tweaked by changes to how it is stored and how efficiently it is transcribed. The presence of iron is a major trigger for the production of 
ferritin [15]. Ferritin serves to store iron in a non-toxic form, to deposit it in a safe form, and to transport it to areas where it is required. Free iron is toxic to cell as it acts as a catalyst in the formation of free radicals from reactive oxygen specie via the Fenton reaction [16]. Within cells, iron is stored in a Protein complex as ferritin or Haemosiderin. Apoferritin binds to free ferrous iron and stores it in the ferric state. Ferritin accumulates within the cells of the reticuloendothelial system. Protein aggregates are formed as haemosiderin. Iron in ferritin or haemosiderin can be extracted for release by the reticuloendothelial cells although haemosiderin is less readily available [17]. In immune response, ferritin concentrations increase drastically in the presence of an infection or cancer. Endotoxin is an up-regulator of the gene coding for ferritin, thus causing the concentration of ferritin to rise. By contrast, organisms such as Pseudomonas, although possessing endotoxin, cause serum ferritin levels to drop significantly within the first 48 hours of infection. Thus, the iron stores of the infected body are denied to the infective agent, impeding its metabolism [18]. In response to stress, the concentration of ferritin has been shown to increase in response to stresses such as anorexia [19]. In diagnosis, serum ferritin levels are measured in medical laboratories as part of the iron studies workup for anaemia and for restless leg syndrome. The ferritin levels measured usually have a direct correlation with the total amount of iron stored in the body. However, ferritin levels may be artificially high in cases of anaemia of chronic disease where ferritin is elevated in its capacity as an acute phase protein and not as a marker for iron overload.

\section{Use of Serum Ferritin as Index of Anaemia Diagnosis}

Ferritin levels are considered the gold standard for the diagnosis of iron-deficiency anaemia. The diagnosis of iron deficiency anaemia using iron related parameter is associated with a number of challenges. Serum iron levels are not helpful by themselves because they vary with time of the day and due to various systemic insults [20]. Another challenge is that although serum iron levels can be measured directly in the blood, but these levels increase immediately with iron supplementation (patient must stop supplements for 24 hours), and pure blood-serum iron concentration in any case is not as sensitive as a combination of total serum iron along with a measure of the serum iron-binding protein levels (total iron binding capacity or TIBC). The ratio of serum iron to TIBC (transferrin saturation index or percent) is the most specific indicator of iron deficiency, when it is sufficiently low. The iron saturation (or transferrin saturation) of $<5 \%$ almost always indicates iron deficiency, while levels from $5 \%$ to $10 \%$ make the diagnosis of iron deficiency possible but not definitive.
Saturations over $12 \%$ (taken alone) make the diagnosis unlikely. Normal saturations are usually slightly higher for women $(>12 \%)$ than for men $(>15 \%)$, but this may indicate simply an overall slightly poorer iron status for women in the normal population. Ferritin can be detected in serum and correlates well with body iron stores. Ferritin is decreased with iron deficiency anaemia and is increased with elevated total body stores of iron. Ferritin is also an acute phase protein, and hyperferritinaemia can occur with underlying disease, such as inflammatory disease, neoplasia, liver disease, or haemolytic disease. Previous report indicates that virtually all patients with serum ferritin concentrations less than $15 \mathrm{ng} / \mathrm{mL}$ are iron deficient, with a sensitivity and specificity of $59 \%$ and $99 \%$, respectively [21]. A cut-off limit of $30 \mathrm{ng} / \mathrm{mL}$ may increase its sensitivity to $92 \%$ [22].

An equivocally low plasma ferritin concentration confirms iron deficiency, but a normal or high one should not be assumed to exclude it bone marrow film for iron staining may be needed to confirm the diagnosis of iron deficiency in ambiguous cases. In the presence of infection or malignancy, plasma iron concentration and percentage saturation may be lower than expected. However, plasma ferritin concentrations are high in most patients with iron overload (whether reticuloendothelial of parenchymal). It is rare in hereditary haemachromatosis to have a normal plasma ferritin concentration, although this may occur in the early stages, when the iron saturation may be useful diagnostically. Serum or plasma ferritin level decreases in iron deficiency anaemia, increases in sideroblastic anaemia and sometimes chronic diseases. However, it may be normal in chronic diseases as in thalassaemia trait [23].

\section{High Serum Ferritin}

If ferritin level is high, there is iron in excess or else there is an acute inflammatory reaction in which ferritin is mobilized without iron excess. For example, Ferritins may be high in infection without signaling body iron overload. Ferritin is also used as a marker for iron overload disorder, such as haemochromatosis or haemosiderosis. Adult-onset stills disease, some porphyria, and haemophagocytic or macrophage activation syndromes are diseases in which the ferritin level may be abnormally raised. As ferritin is also an acute phase reactant, it is often elevated in the course of disease. A normal C-reactive protein can be used to exclude elevated ferritin caused by acute phase reactions. According to a study of anorexia nervosa patients, ferritin can be elevated during periods of acute malnourishment, perhaps due to iron going into storage as intravascular volume and thus the number of red blood cells falls [24]. 
Recent study suggests that due to the catabolic nature of anorexia nervosa, isoferritins may be released. Furthermore, ferritin has significant non-storage roles within the body, such as protection from oxidative damage. The rise of these isoferritins may contribute to an overall increase in ferritin concentration. The measurement of ferritin through imunoassay or immunoturbidimetric methods may also be picking up these isoferritins thus not a true reflection of iron storage status [25].

\section{Low Serum Ferritin}

If the ferritin level is low, there is a risk for lack of iron, which could lead to laboratory test for iron deficiency anaemia [21]. In the setting of anaemia, low serum ferritin is the most specific. However, it is less sensitive, since its levels are increased in the blood by infection or any type of chronic inflammation [26] and these conditions may convert what would otherwise be a low level of ferritin from lack of iron, into a value in the normal range. For this reason, low ferritin levels carry more information than those in the normal range. Low ferritin may also indicate hypothyroidism, vitamin C deficiency or coeliac disease. In adolescents and teenagers, ferritin levels that are low but yet above those causing anaemia and sickness (12 to $50 \mathrm{ng} / \mathrm{mL}$ ) Mark, et al. This may cause symptoms of restless leg syndrome [27]. A falsely low blood ferritin (equivalent to a false positive test) is very uncommon [26] but can result from a hookworm effect of the measuring tools in extreme cases [17].

\section{Materials and Method}

\section{Sample Collection and Processing}

Blood samples were collected by clean venipuncture and was delivered into plain plastic tube container. It was allowed to clot and the serum was obtained. Serum was tested for serum ferritin using the ACCU Diag ${ }^{\mathrm{TM}}$ ELISA Ferritin kit (Cortez Diagnostics, U.S.A.).

\section{Principle of the Test}

The ferritin qualitative test kit is based on a solid phase enzyme-linked immunosorbent assay. The assay system utilizes one anti-ferritin antibody for solid phase (microtiter wells) immobilization and another mouse monoclonal anti-ferritin antibody in the antibodyenzyme (horseradish peroxidase) conjugate solution. The test sample was allowed to react simultaneously with the antibodies, resulting in the ferritin molecules being sandwhiched the solid phase and the enzymelinked antibodies. After 60 minutes incubation at room temperature, the wells are washed to remove unbound labeled antibodies. A solution of TMB was added and incubated for 20 minutes, resulting in the development of a blue colour. The colour development was stopped with the addition of two normal ( $2 \mathrm{~N})$ hydrochloric acid $(\mathrm{HCl})$, and the colour was changed to yellow and measure spectrophotometrically at $450 \mathrm{~nm}$. The concentration of ferritin was directly proportional to the colour intensity of the test sample.

\section{Study Design and Subjects}

This study is a comparative study of serum ferritin level among pre-and postmenopausal women attending Usmanu Danfodiyo University Teaching Hospital Sokoto. One hundred and fifty women made of 75 premenopausal women and 75 postmenopausal women attending Usmanu Danfodiyo University Teaching Hospital Sokoto constituted the subjects for this study.

\section{Site of the Study}

Usmanu Danfodiyo University Teaching Hospital Sokoto is located in Sokoto State. Sokoto is located at the extreme Northwest of Nigeria between longitude $05^{0}$ and $11^{\circ}$ to $13^{\circ}$ and $03^{\circ}$ East and between latitude $13^{0}$ and $00^{\circ}$ to $13^{\circ}$ and $06^{\circ}$ North. The state shares border with the Republic of Niger to the North, Kebbi State to the West and Southeast and Zamfara State to the East. The state covers land area of about $60.33 \mathrm{~km}_{2}$. Sokoto state had a population of 3.6 million (Sokoto Diary, 2008). The indigenous inhabitants of the area are the Hausa and Fulani. Other ethnic group resident in the area includes Igbo, Yoruba, Ebira, and Igala etc. Hausa is the commonly spoken language. This study was conducted in Usmanu Danfodiyo University Teaching Hospital using pre-and postmenopausal women as the subject of study.

Inclusion criteria: Inclusion criteria included age $\geq 18$ years, non-pregnant and willing to offer written informed consent after counselling.

Exclusion criteria: Non-consenting, non -pre-and postmenopausal women, pregnant women and girls below the age of 18 years will be excluded for this study.

Informed consent: Written informed consent was obtained from the patients prior to the commencement of the study.

Sample size calculation: The prevalence of low and high serum ferritin level of $17.7 \%$ and $23.1 \%$ were recorded in pre-and postmenopausal Danish women [28].

The sample size for both pre-and postmenopausal women was calculated using the following formula.

$\mathrm{n}=\mathrm{Z} 2 \mathrm{pq} / \mathrm{d} 2$

$\mathrm{n}=$ Minimum required sample size 
$\mathrm{z}=$ Standard normal deviation at $95 \%$ confidence interval $=(1.96)$

$\mathrm{p}=$ Proportion of success or prevalence

$\mathrm{q}=$ Proportion of failure (1-p)

$\mathrm{d}=$ Precision, tolerable margin of error expected $(0.05)$

\section{For pre-menopausal women}

Data

$\mathrm{z}=(1.96) 2=3.84$

$\mathrm{p}=17.7 \%[28]$

$\mathrm{q}=(1-0.18)=0.82$

$\mathrm{d}=(0.05) 2=0.0025$

$\mathrm{n}=(1.96) 2(0.178)(0.177 /(0.05) 2$

$n=224$

\section{For postmenopausal women}

Data

$\mathrm{z}=(1.96) 2=3.84$

$\mathrm{p}=23.1 \%[28]$

$\mathrm{q}=(1-0.231)=0.769$

$\mathrm{d}=(0.05) 2=0.0025$

$\mathrm{n}=(1.96) 2(0.231)(0.769) /(0.05) 2$

$\mathrm{n}=273$

Sample size $=224$ pre-and 273 post menopausal women attending Usmanu Danfodiyo University Teaching Hospital were used for this study.

Calculation: Using the mean absorbance value (A450) for each set of reference standards, concentration of ferritin (in $\mathrm{ng} / \mathrm{ml}$ ) of control and patient samples was determined.

\section{Reference and Sensitivity}

Male $=32.0-501.0 \mathrm{ng} / \mathrm{ml}$

Female $=3.5-223.5 \mathrm{ng} / \mathrm{ml}$

The minimal sensitivity is $5.0 \mathrm{ng} / \mathrm{ml}$.

Data Management: Data collected was analyzed using SPSS version 20 computer statistical software package. The results were expressed as mean \pm SD. Comparisons between populations were made using the Student's ttest for parametric data and the Chi-Square test for nonparametric. A value of $<0.05$ denoted a statistically significant difference.

Ethical Clearance: The approval for the entire study was obtained from the ethical committee in Usmanu Danfodiyo University Teaching Hospital, Sokoto, Nigeria.

\section{Results}

In this study, the serum ferritin levels of one hundred and fifty women (75 pre-menopausal and 75 postmenopausal) attending Usmanu Danfodiyo University Teaching Hospital Sokoto North Western Nigeria aged 18-49 and 50- 87 years with mean age of $43.99 \pm 19.22$ were investigated. The sociodemographic characteristic of the subjects is shown in Table 1.

The serum ferritin levels were compared among the premenopausal and postmenopausal subjects. The serum ferritin was significantly higher among postmenopausal women $47.38 \pm 43.00$ compared to premenopausal women $21.96 \pm 20.15(\mathrm{p}=0.01)$. Table 2 shows the comparison of the mean serum ferritin level between pre-and postmenopausal women.

The prevalence of anaemia was compared among premenopausal and postmenopausal. The prevalence of anaemia based on low serum ferritin level was higher among premenopausal women (8.7\%) compared to postmenopausal women $(2.7 \%)$. Table 3 shows the prevalence of anaemia based on ferritin $<3.5 \mathrm{ng} / \mathrm{ml}$ among pre-and postmenopausal women.

The ferritin level among premenopausal and postmenopausal was compared based on ethnicity. Low ferritin level $<3.5 \mathrm{ng} / \mathrm{ml}$ was higher among Hausa /Fulani $(6.02 \%)$ compared to other ethnic groups. The difference however was not statistically significant $(p=0.91)$. Table 4 show the effect of ethnicity on serum ferritin level between pre-and postmenopausal women.

Low ferritin level was higher among pre-and postmenopausal women in the 25-34 years age group compared to other age group. The difference however was not statistically significant. (p-0.89). However, when categorized based on pre-and postmenopausal women there was a statistically significant difference $(p=0.01)$. Table 5 shows the effect of age on the serum ferritin level between pre-and postmenopausal women.

The ferritin level among premenopausal and postmenopausal was compared based on educational level. Low ferritin level $<3.5 \mathrm{ng} / \mathrm{ml}$ was higher among subjects with no formal education and those with tertiary education compared to those with primary and secondary. The difference however was not statistically significant $(\mathrm{p}=0.69)$. Table 6 show the effect of educational level on the serum ferritin level between pre-and postmenopausal women.

\begin{tabular}{|c|c|c|}
\hline Variable & Frequency & Percentage (\%) \\
\hline Age groups (years) & & 23.3 \\
\hline $15-24$ & 35 & 17.3 \\
\hline $25-34$ & 26 & \\
\hline
\end{tabular}




\begin{tabular}{|c|c|c|}
\hline $35-44$ & 12 & 8 \\
\hline $45-54$ & 21 & 14 \\
\hline $55-64$ & 32 & 10 \\
\hline $65-74$ & 15 & 4.7 \\
\hline $75-84$ & 7 & 1.3 \\
\hline $85-94$ & 2 & \\
\hline Ethnic groups & & 94 \\
\hline Hausa/Fulani & 141 & 2 \\
\hline Yoruba & 3 & 3.3 \\
\hline Igbo & 5 & 0.7 \\
\hline Bendel & 1 & 10.7 \\
\hline Level of Education & 16 & 15.3 \\
\hline Primary & 23 & 21.3 \\
\hline Secondary & 32 & 52.7 \\
\hline Tertiary & 79 & 60.7 \\
\hline Non-formal & & 2.7 \\
\hline Occupation & 91 & 17.3 \\
\hline House wife & 4 & 19.3 \\
\hline Civil servant & 26 & 100 \\
\hline Student & 29 & \\
\hline Trader & 150 & \\
\hline Total & & \\
\hline
\end{tabular}

Table1: Sociodemographic characteristics of the study population.

Table 1 above shows the Sociodemographic characteristics of the study population. The majority of the premenopausal women falls between the age range of $15-2435(35 \%)$ and that of postmenopausal women was 55-64 32(21.3\%). Based on ethinicity Hausa/Fulani have the highest percentage $141(94.0 \%)$. Subjects with no formal education have the highest percentage based on educational level $79(52.7 \%)$. House wife have the highest percentage among the subjects based on occupation 91(60.7\%).

\begin{tabular}{|c|c|c|c|c|c|}
\hline $\begin{array}{c}\text { Menopausal Status of the } \\
\text { Participant }\end{array}$ & $\mathbf{N = 1 5 0}$ & Mean & Std. Deviation & t-test & p-value \\
\hline Premenopausal Women & 75 & 21.96 & 20.15 & 4.31 & 0.01 \\
\hline Postmenopausal Women & 75 & 47.38 & 43 & & \\
\hline
\end{tabular}

Table 2: Comparison of mean serum ferritin level between pre-and post-menopausal women.

$\mathrm{N}=$ Number of subjects.

Table 2 above the shows comparison of mean serum ferritin level between pre-and post menopausal women, revealed a significant difference $(\mathrm{p}=0.01)$. The mean serum ferritin in pre and postmenopausal women was $(21.96 \pm 20.15)$ and $(47.38 \pm 43.00)$ respectively.

\begin{tabular}{|c|c|c|c|}
\hline & Normal ferritin level & Low ferritin level & Percentage (\%) \\
\hline Premenopausal Women & $\mathbf{6 9}$ & $\mathbf{6}$ & $\mathbf{8 . 7}$ \\
\hline Postmenopausal Women & $\mathbf{7 3}$ & $\mathbf{2}$ & $\mathbf{2 . 7}$ \\
\hline
\end{tabular}

Table 3: Prevalence of anaemia due to low serum ferritin level in pre-and postmenopausal women.

Table 3 above shows the prevalence of anaemia due to low serum ferritin level between pre-and postmenopausal women. The prevalence was $6(8.7 \%)$ and $2(2.7 \%)$ respectively. 


\begin{tabular}{|c|c|c|c|c|c|c|c|}
\hline & \multicolumn{7}{|c|}{ Ethnic groups of the Participants } \\
\hline & Hausa/Fulani & Yoruba & Igbo & Bendel & Chi-Square & $\begin{array}{l}\text { Degree of } \\
\text { freedom }\end{array}$ & P-value \\
\hline & $(\mathrm{N})$ & $(\mathrm{N})$ & $(\mathrm{N})$ & $(\mathrm{N})$ & & & \\
\hline $\begin{array}{c}\text { Normal } \\
\text { ferritin level }\end{array}$ & 142 & 3 & 5 & 1 & 0.52 & 3 & 0.91 \\
\hline $\begin{array}{c}\text { Low ferritin } \\
\text { level }\end{array}$ & 8 & 0 & 0 & 0 & & & \\
\hline
\end{tabular}

Table 4: The effect of ethinicity on serum ferritin level between pre-and postmenopausal women $\mathrm{N}=$ Number of subjects.

Table 4 above shows effect of ethinicity on serum ferritin level between pre-and postmenopausal women,

revealed no significance difference $(\mathrm{p}=0.91)$.

\begin{tabular}{|c|c|c|c|c|c|}
\hline Age groups & Normal ferritin level & Low ferritin level & Chi-Square & Degree of freedom & P-value \\
\hline $15-24$ & 32 & 3 & 2.9 & & 0.89 \\
\hline $25-34$ & 24 & 2 & & & \\
\hline $35-44$ & 11 & 1 & & & \\
\hline $45-54$ & 20 & 1 & & & \\
\hline $55-64$ & 31 & 1 & & & \\
\hline $65-74$ & 15 & 0 & & & \\
\hline $75-84$ & 7 & 0 & & & \\
\hline $85-94$ & 2 & 0 & & & \\
\hline
\end{tabular}

Table 5: The effect of age on the serum ferritin level between pre-and postmenopausal women.

Table 5 above shows the effect of age on serum ferritin level between pre-and postmenopausal women, revealed no significance difference $(\mathrm{p}=0.89)$.

\begin{tabular}{|c|c|c|c|c|c|}
\hline \multirow{2}{*}{ Educational level } & Normal ferritin level & Abnormal ferritin level & \multirow{2}{*}{ Chi-Square } & $\begin{array}{c}\text { Degree of } \\
\text { freedom }\end{array}$ & \begin{tabular}{c} 
P-value \\
\cline { 2 - 5 }
\end{tabular} \\
\cline { 2 - 5 } & $\mathbf{N = 1 4 2} \mathbf{( \% )}$ & $\mathbf{N = 8 ( \% )}$ & 1.48 & 3 & 0.69 \\
\hline Primary & $15(10.6)$ & $1(12.5)$ & & & \\
\hline Secondary & $22(15.5)$ & $1(12.5)$ & & & \\
\hline Tertiary & $29(20.4)$ & $3(37.5)$ & & \\
\hline
\end{tabular}

Table 6: Effect of level of education on serum ferritin in pre-and postmenopausal women $\mathrm{N}=$ Number of subjects.

Table 6 above shows the effect of level of education on serum ferritin between pre-and post menopausal women. There was no statistically significant difference in the level of education on serum ferritin level in preand postmenopausal women $(\mathrm{p}=0.69)$.

\section{Discussion}

Ferritin is an essential component of the plasma and it may potentially cause health problems in women if it exceeds the normal physiological range. In this present study serum ferritin levels of one hundred and fifty women ( 75 pre-menopausal and 75 post-menopausal) attending Usmanu Danfodiyo University Teaching Hospital Sokoto North Western Nigeria was monitored.
Finding from this study indicates that premenopausal women had lower serum ferritin compared to postmenopausal women. Of the premenopausal women $8 \%$ had depleted iron stores defined as serum ferritin level less than $3.5 \mathrm{ng} / \mathrm{ml}$ (lower limit of the reference range) compared to $2.7 \%$ among postmenopausal women. This finding is consistent with previous report [28] who assessed the iron status by measuring serum ferritin and haemoglobin ( $\mathrm{Hb}$ ) in a population survey comprising 1,359 non-pregnant Danish women, in age cohorts of $30,40,50$, and 60 years (809 were premenopausal and 550 postmenopausal). Premenopausal women had lower serum ferritin (median 37 micrograms/l) than postmenopausal women (median 71 micrograms/l; p <0.001). Finding from this study is consistent with a previous report 
which indicated that young premenopausal women are among those at greatest risk for iron deficiency anaemia due to low ferritin level [10]. Finding from this study is consistent with the recommendation that ferritin measurements could be useful tools to assess irondisease among pre-and post menopausal women.

There are several factors that may responsible for the low ferritin and high prevalence of iron deficiency anaemia among pre-menopausal women compared to post menopausal women; menstruation and pregnancy [29]. Factors such as use of hormone replacement therapy and occult bleeding (from a gastrointestinal ulcer) [30] may be responsible for anaemia and low ferritin among post menopausal women. Other factors reported to affect iron marker levels in postmenopausal women include blood donation, aspirin use, intake of heme iron, body mass index, and alcohol intake [30].

Anaemia is a major public health concern worldwide, especially among women and children. Iron deficiency anaemia (serum ferritin less than 15 micrograms/l) was higher among premenopausal women (2.6\%) compared to postmenopausal women $(0.36 \%)$. This finding is consistent with that of [31] who also assessed iron status by serum ferritin and haemoglobin $(\mathrm{Hb})$ in a population survey comprising 883 non-gravid Danish women in age cohorts of 35, 45, 55, and 65 years. Premenopausal women $(\mathrm{n}=676)$ had lower serum ferritin, median 42 micrograms/l, than postmenopausal women $(\mathrm{n}=207)$, median 80 micrograms $/ \mathrm{l}(\mathrm{p}<$ 0.0001). The corresponding figure in postmenopausal women was $0.5 \%$. He reported that in premenopausal women, serum ferritin levels were strongly dependent on the duration of menstrual bleeding. Also, the finding from this study is consistent with that previously reported by Milman [32] who reported a gender and age-related changes in iron status and body iron reserves in a broad spectrum of the Danish population. Among 30 to 50-year-old premenopausal women, the prevalence of ample iron stores was $0.49 \%$, whereas $18 \%$ had exhausted iron reserves and $2.6 \%$ had iron deficiency anaemia. After menopause, serum ferritin gradually rose and approached male levels. Among 60 to 70-year-old postmenopausal women, $3.0 \%$ had ample iron stores, $2.3 \%$ had depleted stores and none had iron deficiency anaemia. My finding was in line with that reported by Cook, et al. [33] who reported that in the United States, low iron stores (ferritin< $12 \mu \mathrm{g} / \mathrm{l}$ ) occur in $21.3 \%$ of women aged 18 to 44 years, in $5.9 \%$ of women aged 45 to 64 years, and in $1.6 \%$ of men aged 18 to 64 years.

Finding from this study indicated age-related differences in the serum ferritin levels of pre-and postmenopausal women in the 25-34 years age group compared to other age group. This finding is consistent with the previous findings of Milman, et al. [28] who reported that Premenopausal women had lower serum ferritin (median 37 micrograms/l) than postmenopausal women (median 71 micrograms/l; p less than 0.0001). Of the premenopausal women, $17.7 \%$ had S-ferritin less than 15 micrograms/l (i.e., depleted iron stores), and $23.1 \%$ serum ferritin of $15-30$ micrograms/l (i.e., small iron stores). The use of oral contraceptives had a marked influence on iron stores; premenopausal women taking the pill had higher serum ferritin and a lower frequency of depleted iron reserves than nonusers ( $p$ less than 0.01). Postmenopausal estrogen treatment had no influence on serum ferritin or $\mathrm{Hb}$ [28].

Finding from this study indicated a difference in the number of pre-and postmenopausal women with low ferritin level based on their educational level $(p=0.69)$. This finding was consistent with that reported by Fatemeh, et al. [34] in comparison of the serum iron, ferritin levels and total iron-binding capacity between pregnant women with and without gestational diabetes. The finding showed no significant difference between the two groups in terms of parities and educational level. The possible reason for this may be due to the fact that educational level has no effect on serum ferritin level.

Observation from this study indicated a difference in the number of pre-and postmenopausal women with low ferritin level based on their ethnic groups $(p=0.69)$. This finding agrees with the previous finding reported by Hughes 1993-1995 who reported in the National University of Singapore Heart study survey of cardiovascular risk factors in persons aged 30-69 years, from the general population of Singapore with 957 persons having measurements of serum ferritin. For males aged 30-69 years mean serum concentrations were highest in Chinese $(326 \mu \mathrm{g} / \mathrm{l})$, followed by Malays $(175 \mu \mathrm{g} / \mathrm{l})$ and then Indians $(132 \mu \mathrm{g} / \mathrm{l})$. For premenopausal women aged 30-49 years mean levels were higher in Chinese $(61 \mu \mathrm{g} / \mathrm{l})$ and Malays $(55 \mu \mathrm{g} / \mathrm{l})$ than Indians $(30 \mu \mathrm{g} / \mathrm{l})$ and likewise for the postmenopausal women aged 50-69 years age group where the mean values were $144 \mu \mathrm{g} / \mathrm{l}$ for Chinese, $141 \mu \mathrm{g} / \mathrm{l}$ for Malays and $85 \mu \mathrm{g} / \mathrm{l}$ for Indians.

The lower levels of serum ferritin in Indians could be due to reduced dietary intake or impaired absorption of iron. It was found in a study of females in Britain, that Indians had lower levels of serum ferritin than whites, Blacks and Orientals, which was considered probably due to reduced iron intake [35-56].

The ferritin level among premenopausal and postmenopausal was compared based on ethnicity. Low ferritin level $<3.5 \mathrm{ng} / \mathrm{ml}$ was higher among Hausa 
/Fulani (6.02\%). High incidence of under nutrition, poor diet, and concurrent micronutrient deficiencies may be responsible for the high number of pre-and postmenopausal women of Hausa /Fulani ethnic groups with low ferritin levels.

\section{Conclusion and Recommendations}

This study has shown that serum ferritin and anaemia based on serum ferritin level of $<3.5 \mathrm{ng} / \mathrm{ml}$ was significantly higher among premenopausal compared to postmenopausal women. Ferritin level $<3.5 \mathrm{ng} / \mathrm{ml}$ was higher among Hausa /Fulani (6.02\%) and among preand women in the 25-34 years age group. There were age-related differences on the serum ferritin level of pre-and postmenopausal women. Ferritin level $<3.5 \mathrm{ng} / \mathrm{ml}$ was higher among subjects with no formal education and those with tertiary education compared to those with primary and secondary.

From this study it is therefore recommended that that the serum ferritin should be used for the diagnosis and monitoring of iron deficiency anaemia in pre-and postmenopausal women, for all ages serum ferritin level of less than $3.5 \mathrm{ng} / \mathrm{ml}$ should be used as cutoff for the diagnosis of depleted iron store.

\section{Limitation}

The major limitation was the sample size studied for the purpose of this apparently comparative study. The evaluable data was for 150 participants (pre- and menopausal women) instead of the calculated 224 and 273 for pre-and post-menopausal respectively.

\section{References}

1. Casiday R, Fray R (1995) Iron Use and Storage in the Body: ferritin and Molecular Respirations. Tutorial Department of Chemistry, Washington University St. Louis, MO 63130.

2. Wang W, Knovich MA, Coffman LG, Torti FM, Torti SV (2010) Serum ferritin: Past, present and future. Biochem Biophys Acta 1800(8): 760-769.

3. (2000) World Health Organisation (WHO) The global picture of anaemia. Technical report series 2000: Report of a WHO scientific group, Geneva: 1523.

4. Pinn VW (2004) A new mosaic for women's health. Journal of Dental Education 68: 7-14.

5. Hickey M, Davis SR, Sturdee DW (2005) Treatment of Menopausal Symptoms: what Shall We do. Lancet 366: 409-421.
6. Nelson HD (2008) Menopause. Lancet 371(9614): 760-770.

7. Garnero P, Sorney-Rendu E, Chapuy MC, Delmas PD (1996) Increase Bone Turn Over in Late Postmenopausal Women Is a major Determinant of Osteoporsis. J Bone Miner Res 11(3): 337-349.

8. Ravn P, Bidstrup M, Wasnich RD, Davis JW, Mcclung $M R$, et al. (1999) Alandronate and oestrogenprogestin in the long term prevention of bone loss: four-year results from the early postmenopausal intervention cohort study. A randomized, controlled trial. Ann Intern Med 131(12): 935-942.

9. Zimmermann MB, Hurrell RF (2007) Nutritional iron deficiency. Lancet 370(9586): 511-520.

10. Dandekar US (2009) Association between Serum Ferritin and Body Composition in Young Women. University of Massachusetts. Masters Theses 101(9): 3756-3757.

11. Andrews SC, Arosio P, Bottke W, Briat JF, von Darl M, et al. (1992) Structure, function and evolution of ferritins. J Inorg Biochem 47(3-4): 161-174.

12. Condrad ME, Ubreit JN (2000) Disorders of iron metabolism. New England Journal of Medicine 342(17): 1294.

13. Fleming RE, Bacon BR (2005) Oechestration of iron haemostasis. N Engl J Med 352(17): 1741-1744.

14. Andrews NC (2004) Anaemia of inflammation: the cytokinne-hepcidin link. J Clin Invest 113(9): 1251 1253.

15. Theil E (1987) Ferritin structure, gene regulation and cellular function in animals, plant and microorganisms. Ann Rev Biochem 56(1): 289-315.

16. Orino K, Lehman L, Tsuji Y, Ayaki H, Torti SV, et al. (2001) Ferritin and the response to oxidative stress. J Biochem 357(1): 241-247.

17. Burnett D, John R (1999) The science of laboratory diagnosis in medical media. African Medical Laboratory Journal 321: 4-6.

18. Minqin R, Rajendran $\mathrm{R}$, Pan $\mathrm{N}$, Tan $\mathrm{BK}$, Ong WY, et al. (2005) The iron chelator desferrioxamine inhibitants atherosclerotic lesion development and decreases lesion iron concentrations in the cholesterol. Free Radic Biol Med 38(9): 1206-1211.

19. Larade K, Storey KB (2007) Accumulation and translation of ferritin heavy chain transcripts 
following anoxia exposure in a marine invertebrate. J Exp Biol 207(8):1353-1360.

20. Favier A, Ruffieux D (1983) Physiological variation of serum levels of copper, Zinc, Iron, Manganese. Biomed Pharmacother 37(9-10): 462-466.

21. Guyatt GH, Oxman AD, Ali M, Willian A, McIlroy W, et al. (1992) Laboratory diagnosis of iron deficiency anaemia: an over view. J Gen Intern Med 7(2): 145153.

22. Mast AE, Blinder AM, Chumley C, Scott MG (1998) Clinical utility of the soluble transferring receptor and comparison with serum ferritin in several populations. Clin Chem 44(1): 45-51.

23. Monica C (2010) District laboratory practice in tropical countries. Second edition update pp: 278279.

24. Kennedy A, Kohn M, Lammi A, Clarks S (2004) Iron status and haematological changes in adolescent female inpatients with anorexia nervosa. J Paediatr Child Health 40(8): 430-432.

25. Trans J, Story C, Moore D, Metz M (2013) Uncrypted increase ferritin concentration in patients with anorexia nervosa 50: 504-506.

26. Frank R, Bryan R (1997) Interpretation of biochemical tests for iron deficiency diagnostic difficulties related to limitations of individual tests. Australian Prescriber 20: 74-76.

27. Kryger MH, Otake K, Foerster J (2002) Low body stores of iron and restless legs syndrome: a correctable cause of insomnia in adolescents and teenagers. Sleep Med 3(2): 127-132.

28. Milman N, Kirchhoff M, Jørgensen T (1992) Iron status markers, serum ferritin and hemoglobin in 1359 Danish women in relation to menstruation, hormonal contraception, parity, and postmenopausal hormone treatment. Ann Haematol 65(2): 96-102.

29. Harvey LJ, Armah CN, Dainty JR, Foxall RJ, John LD, et al. (2005) Impact of menstrual blood loss and diet on iron deficiency among women in the UK. Br J Nutr 94(4): 557-564.

30. Liu JM, Hankinson SE, Stampfer MJ, Rifai N, Willett WC, et al. (2003) Body iron stores and their determinants in healthy postmenopausal US women. Am J Clin Nutr 78(6): 1160-1167.

31. Milman N, Rosdah l N, Lyhne N, Jørgensen $\mathrm{T}$, Graudal N (1993) Iron status in Danish women aged 35-65 years. Relation to menstruation and method of contraception. Acta Obstet Gynecol Scand 72(8): 601-605.

32. Milman N (1996) Serum ferritin in Danes: studies of iron status from infancy to old age, during blood donation and pregnancy. Int J Hematol 63(2): 103135 .

33. Cook JD, Skikne BS, Lynch SR, Reusser ME (1986) Estimate of iron sufficiency in the United State population. Blood 68(3): 726-731.

34. Fatemeh NA, Zahra B, Shabnam O, Majid S, Karimollah HT, et al. (2013) Comparison of the serum iron, ferritin levels and total iron-binding capacity between pregnant women with and without gestational diabetes. J Nat Sci Biol Med 4(2): 302-305.

35. Burt MJ, Halliday JW, Powell LW (1993) Iron and Coronary Heart Disease. BMJ 307(6904): 575-576.

36. Ajmera AV, Shastri GS, Gajera MJ, Judge TA (2012) Sub-optimal response to Ferrous sulfate in irondeficient patients taking omeprazole. Am J Ther 19(3): 185-189.

37. (2008) American College of Obstetricians and Gynecologists. ACOG practice.

38. Baker RD, Greer FR (2010) Committee on Nutrition. American Academy of Pediatrics on Gastroenterology. Hepatology and Nutrition 126(6): 1217-1231.

39. Berlin MT, Abeche AM (2011) Evolutionary approach to medicine. J South Med 94(1): 26-32.

40. Camschella C (2005) Understanding iron haemostasis through genetic analysis of haemochromatosis and related disorders. Blood 106(12): 3710-3711.

41. Camschella C, Shrier SL (2011) Regulation of iron balance up to date. Retrieved 2012.

42. Center for Disease Control. (CDC,2002) Use of contraception and use of family planning in the United States.

43. Cho GJ, Shin JH, Yi KW, Park HT, Kim T, et al. (2011) Serum ferritin levels are associated with metabolic syndrome in postmenopausal women but not in premenopausal women. Menopause 18(10): 11201124. 
44. Clark SF (2009) Iron deficiency anaemia. Diagnosis and management. Current Opinion in Gastroenterology 25(2): 122-128.

45. Eichbaum Q, Foran S, Dzik S (2003) Is iron gluconate really safer than iron? Blood 101(9): 3756-3757.

46. Frazer DM, Anderson GJ (2005) Iron imports I intestinal iron absorption and its regulation. Am J Physiol, Gastrointest Liver Physiol 289(4): 631-635.

47. Goddard AF, James MW, McIntyre AS, Scott BB (2011) Guidelines for the management of iron deficiency anaemia. Gut 60(10): 1309-1316.

48. Huang $X$ (2008) Does iron have a role in breast cancer? Lancet Oncol 9(8): 803-807.

49. Hughes K (1998) Serum Ferritin and Iron Status in the General Population of Singapore , 1993 to 1995. Ann Acad Med Singapore 27(4):507-11.

50. Johnson-Wimbley TD, Graham DY (2011) Diagnosis and management of Iron Deficiency Anaemia In the 2st Century. Therap Adv Gastroenterol 4(3): 177184.
51. Maslovsky I (2005) Intravenous iron in a primarycare clinic. Am J Hematol 78(4): 261-264.

52. Murphy MF, Wallington TB, Kelsey $\mathrm{P}$, Boulton $\mathrm{F}$ Bruce M, et al. (2001) Guidelines for the clinical use of red cell transfusions. Br J Haematol 113 (1):2431.

53. Baker RD, Greer FR (2010) Diagnosis and prevention of iron deficiency and iron-deficiency anemia in infants and young children (0-3 years of age). Pediatrics 126(5): 1040-1050.

54. Silverstein SB, Rodgers GM (2004) Parenteral iron therapy options. Am J Haematol 7(1): 74-78.

55. (2001) World Health Organization (WHO) Iron deficiency anaemia: Assessment, prevention and control: A Guide for programme managers. Geneva, Switzerland, World Health Organization.

56. Zeleniuch-Jacquotte A, Zhang Q, Dai J, Shore RE, Arslan AA, et al. (2007) Reliability of serum assays of iron status in postmenopausal women. Ann Epidemiol 17(5): 354-358. 